\title{
Laryngopharyngeal Dysesthesia, CTCAE
}

National Cancer Institute

\section{Source}

National Cancer Institute. Laryngopharyngeal Dysesthesia, CT CAE. NCI Thesaurus. Code C143642.

A disorder characterized by an uncomfortable persistent sensation in the area of the laryngopharynx. 